\title{
FAVELA DE PIRAPOZINHO: DIRETRIZES PARA PLANEJAMENTO URBANO
}

Cristiane Santana Rosa Forti ${ }^{1}$, Jéssica Midori Komuro', Everson Rodrigo da Silva ${ }^{1}$

Sibila Corral de Arêa Leão Honda²

${ }^{1}$ Alunos do curso de Arquitetura e Urbanismo da Universidade do Oeste Paulista - UNOESTE. ${ }^{2}$ Docente do curso de Arquitetura e Urbanismo da Universidade do Oeste Paulista - UNOESTE.

\section{RESUMO}

O presente artigo visa a iniciar observações sobre os processos de planejamento e gestão urbanos em cidades de pequeno porte, tendo como foco de discussão a existência e permanência de favelas na estrutura urbana consolidada. Identifica-se que o surgimento de favela não se limita aos grandes centros urbanos, podendo ser percebido também o descaso do Poder Público local das pequenas cidades, tendo como estudo de caso Pirapozinho, município no interior do Estado de São Paulo. Com análise teórica de dados, esta pesquisa busca identificar possibilidades de alteração da realidade municipal, por meio de novas diretrizes de planejamento. A metodologia seguida está apoiada em embasamento teórico e levantamentos de campo na área estudada.

Palavras-chave: Planejamento Urbano, Gestão Urbana, Favela, Revitalização Urbana, Cidades de Pequeno Porte.

\section{INTRODUÇÃO}

A urbanização brasileira tem ocorrido de maneira bastante acentuada, principalmente a partir da segunda metade do século XX, resultando em incremento populacional urbano de mais de 120 milhões de pessoas somente naquele século (MARICATO, 2001).

Os processos de formação urbana que incluíam as camadas mais carentes da população tiveram base na periferização e exclusão habitacional, com forte segregação territorial urbana. As políticas habitacionais também reforçaram essa realidade.

Em relação a questões econômicas, o Brasil cresceu significativamente entre as décadas de 1940 e 1980, mas estagnou entre nas duas décadas seguintes, aumentando a exclusão social, o desemprego, as relações informais de trabalho e a pobreza nas áreas urbanas. Nesse período, segundo dados do IBGE, a população residente em favelas apresentou índice de crescimento superior a 7\% ao ano (MARICATO, 2001).

Importante verificar a conceituação de favelas utilizadas pelo IBGE, desde o final da década de 1940, como aglomerados humanos não urbanizados que possuíssem total ou parcialmente as seguintes características: agrupamentos residenciais com número superior a 50 unidades, com predominância de casebres ou barracões de aspecto rústico; construções sem licenciamento e sem fiscalização, em terrenos de terceiros ou de propriedade desconhecida; ausência de 
arruamento e de infraestrutura urbana, mesmo que parcial (GUIMARÃES, 1953, apud VALLADARES, 2000).

Atualmente, as favelas representam a prevalência de situações de pobreza e de políticas habitacionais ineficazes; sendo que, na maioria dos casos, "estão localizadas em áreas non edificandi, protegidas ambientalmente ou que oferecem risco" (SARAIVA e MARQUES, 2005, p.143). Preteceille e Valladares (2000, p.472) informam:

Uma das principais dimensões que caracteriza, a priori, uma área enquanto favela é a ideia da sua precariedade jurídica. Parece consensual que a favela resultaria de um processo de invasão de terreno, na maioria das vezes desocupado, de propriedade pública ou privada: seus moradores, na origem, teriam um status jurídico ilegal, variando, segundo cada caso, o grau de segurança quanto às possibilidades de permanência na área e seriam proprietários das construções em favela, não dos terrenos onde as mesmas estivessem situadas.

A existência de favelas nas áreas urbanas não se limita aos grandes centros urbanos, reproduzindo-se, inclusive, nas pequenas cidades, como Pirapozinho, município com 24.694 habitantes (IBGE censo 2010), na região oeste do Estado de São Paulo. Dessa forma, esta pesquisa busca identificar a realidade urbana de uma pequena cidade, por meio de uma favela existente, e as ações de inclusão social de sua população.

\section{METODOLOGIA}

A metodologia seguida na pesquisa que embasa este artigo partiu de aprofundamento teórico e conceitual, com levantamento de campo, como identificação da malha urbana de Pirapozinho, discussões e caracterização sobre espaços urbanos, com identificação de regiões e/ou áreas degradadas ou em processo de degradação ou esvaziamento, possibilitando a compreensão sobre os processos urbanos de gestão e planejamento municipais.

\section{PIRAPOZINHO - ANÁLISE URBANA}

Até o início do século XX, o sudoeste do estado de São Paulo ainda era coberto por mata fechada. Por volta de 1850, a área, ainda desconhecida, teve seu primeiro desbravador, que se apossou de uma grande gleba que se estendia do Rio Paranapanema até o Rio do Peixe (GOMES, 1997).

A partir da primeira década do século XX é que a região passa a ser realmente povoada, com a chegada das plantações de café. Por volta de 1930, a Companhia Marcondes de Colonização de Presidente Prudente, abriu uma estrada de rodagem até a margem do rio Paranapanema e surgiu 
um povoado ao longo da estrada que recebeu o nome de São João, sendo patrimônio de Presidente Prudente (GOMES, 1997).

Com o crescimento da malha, em 1936, o povoado foi transformado em distrito de paz, ainda pertencendo a Presidente Prudente, mas já com o nome de Pirapozinho, devido à proximidade do ribeirão de mesmo nome. Com o desenvolvimento agrícola e comercial do distrito, o mesmo foi elevado a Município em dezembro de 1948, sendo efetivamente instalado em 9 de abril de 1949 (XAVIER, 2000).

Segundo IBGE, em 1950, no primeiro levantamento como sede de município, a cidade apresentava população de 28.666 habitantes, apresentando 10,3\% como população urbana, ou seja, 2.955 habitantes. Em 2010, a população era de 24.694 habitantes, decréscimo de 13,85\%, enquanto a população urbana era de 22.874 , com crescimento de $774,0 \%$.

Essa realidade é explicada por Gomes (1997), que no início da década de 1960 começou a decadência da agricultura na região, ocorrendo um grande êxodo rural, com a população urbana crescendo. Como o núcleo urbano de Pirapozinho não conseguiu absorver toda a população rural, o município começou a perder população para cidades maiores.

Durante a década de 1970, a cidade foi se expandindo e o espaço se modificando, surgindo alguns vazios urbanos. Em 1982, foi construído o primeiro conjunto habitacional de habitação social na cidade, o CODESPAULO, atual Jardim Esperança, com 48 unidades. A cidade teve sua maior expansão territorial no final da década de 1980 e início de 1990, e ocorreram processos de doação de terrenos pelo Poder Público municipal (GOMES, 1997).

Importante notar, no entanto, que a estrada de ferro que corta a cidade proporciona uma barreira urbana em Pirapozinho, gerando fortes áreas de segregação socioespacial, ratificando as informações de Jacobs (2011, p. 290), para quem "Certas fronteiras impedem a interação de usos de ambos os lados. Linhas férreas ou vias expressas ou cursos d'água são exemplos comuns."; e de Villaça (2012), que afirma que as cidades geradas a partir da ferrovia são caracterizadas por possuírem um lado mais desenvolvido que o outro, reforçando a segregação.

Segundo Gomes (1997), durante muito tempo a expansão da cidade ficou limitada pela ferrovia e pela rodovia. Mas na década de 1990 esses obstáculos foram rompidos e o crescimento da cidade seguiu em direção a leste, à margem da ferrovia, mas além dela. Nesse período houve uma proliferação de loteamentos para leste e oeste da cidade (Figura 1). Em 1996 foi implantado pela Prefeitura Municipal o Residencial Natal Marrafon, onde 1.000 terrenos foram doados a famílias carentes. 


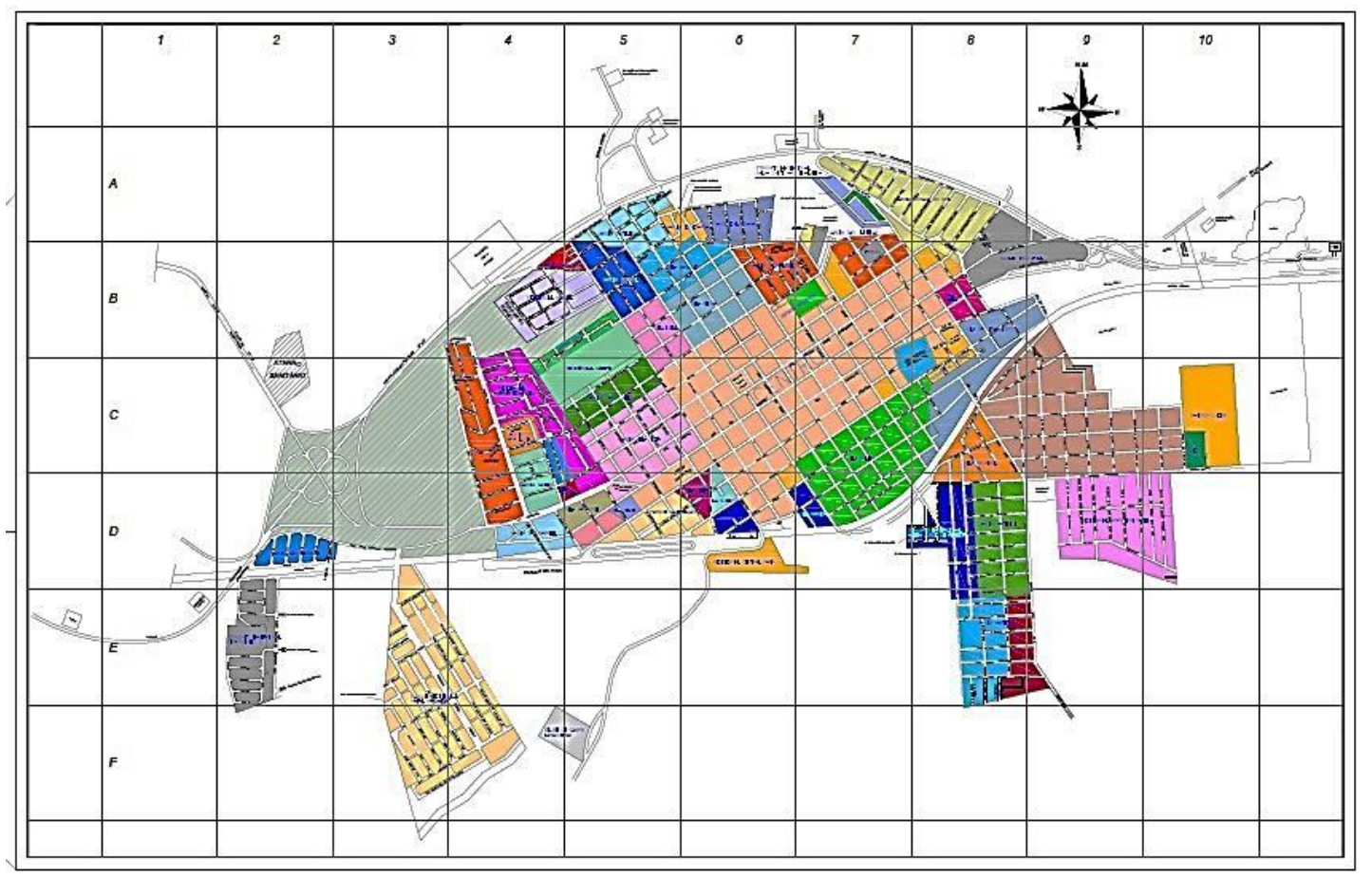

Figura 1. Mapeamento atual dos bairros no município.

Org.: autores, 2012.

Ao mesmo tempo, em 1987, foi iniciado processo de ocupação ilegal de parte do leito da ferrovia, culminando em 91 famílias no ano de 2000, totalizando 309 habitantes (Figura 2). Segundo Xavier (2000), o motivo da fixação das famílias no local foi unicamente financeiro; pois, sem condições de pagar aluguel e sem ter outro lugar onde pudessem construir, viram-se impelidos a ocupar aquele espaço, fazendo surgir uma favela na malha urbana.

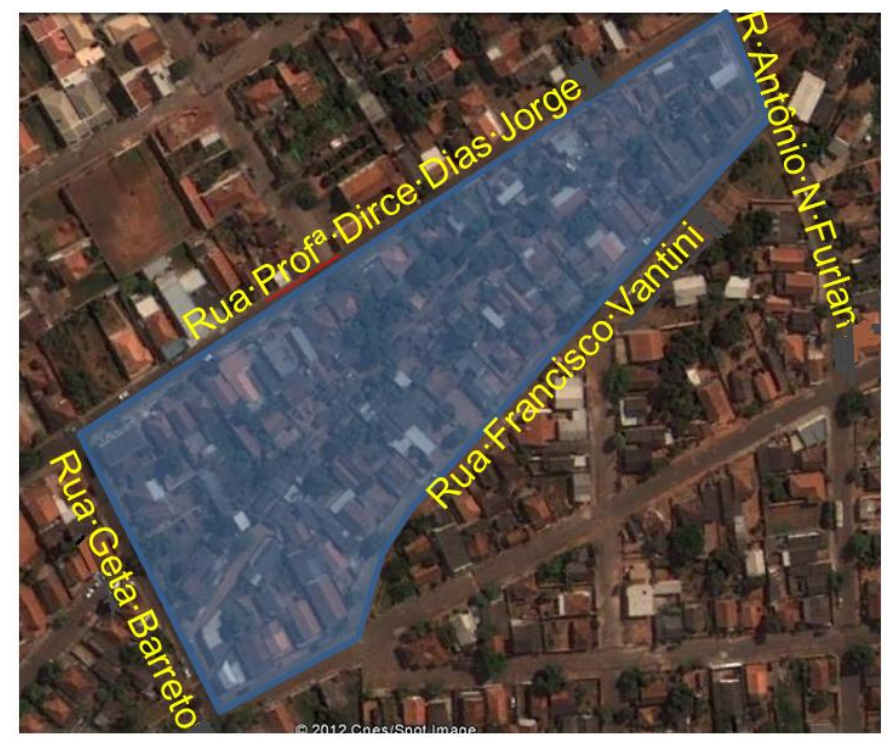

Figura 2. Localização da área de remoção da favela.

Fonte: Google Maps, 2012. 
Ainda de acordo com Xavier (2000), a população residente na favela é bastante carente em relação à infraestrutura urbana, com apenas $26 \%$ dos domicílios servidos de esgoto, e 33\% desses com banheiro; e 32\% das habitações abastecidas por água encanada.

Segundo o dicionário virtual Michaelis, a palavra favela quer dizer "aglomeração de casebres ou choupanas toscamente construídas e desprovidas de condições higiênicas". Mas na prática, as favelas são mais que isso, são moradias feitas com materiais impróprios, dispostas de forma desorganizada e densa, localizadas em regiões privadas de recursos, equipamentos e serviços públicos básicos. São ocupadas por pessoas de baixa renda, que não possuem título de propriedade do imóvel ou terra urbana (MARQUES, 2006).

Urbanisticamente, as favelas possuem um traçado irregular das vias de circulação, que são estreitas e não acompanham o traçado urbano, além dos lotes que são de tamanhos e formas desiguais. Nota-se que nas cidades pequenas ainda há um respeito à propriedade privada por causa da cultura local, mudando apenas esta visão com relação às áreas públicas, principalmente as abandonadas, onde geralmente ocorrem as ocupações (XAVIER, 2000).

\section{PLANEJAMENTO URBANO PONTUAL EM PIRAPOZINHO-SP}

Planejamento urbano, resumidamente, é formulação da intervenção do Estado na produção e reprodução social (DEÁK, 2011). O planejamento é um direito do povo e é instrumento necessário da política urbana que indica o destino pretendido pelos governantes. Mas, geralmente os dirigentes políticos não o fazem por acreditarem ser desnecessário e agem somente conforme os interesses econômicos privados ou quando há interesse eleitoral. Às vezes, há planejamento, mas não é observado ou tem suas normas alteradas para atender interesses econômicos privados e perde o foco de utilidade pública (MARQUES, 2006).

Importante destacar, também, que a partir da Constituição Federal de 1988, o Município passou a ser ente federativo, com a competência para tratar de política urbana, cujo principal instrumento passou a ser o Plano Diretor municipal.

Em relação ao município de Pirapozinho, ele possui Plano Diretor aprovado, Lei Municipal no.3.361/2007, tendo por objetivo promover a justiça social, construir uma sociedade sustentável voltada para o bem-estar e interesse de todos, observando o direito à terra urbanizada, à moradia, ao saneamento ambiental, à infraestrutura urbana, aos serviços comunitários, ao transporte, à acessibilidade e mobilidade, ao trabalho e ao lazer para a atual e futura gerações. 
Verifica-se que a favela da cidade é tratada nesse Plano, no artigo 20, visando à regularização da área em questão:

O Poder Público deverá providenciar, no prazo máximo de 1 (um) ano, a construção de residências unifamiliares, em local apropriado, visando abrigar os moradores que ocupam atualmente o antigo leito ferroviário, situado na Vila São Francisco entre as ruas Antonio Nunes Furlan, Francisco Vantini, Geta Barreto e Professora Dirce Dias Jorge. Esta medida deve ser considerada prioridade máxima do Poder Público municipal.

Observando que o Plano Diretor é de 2007, percebe-se que o artigo 20 não foi cumprido, uma vez que a favela ainda está presente. Tal Plano ainda determina áreas de ocupação prioritárias, áreas de especial interesse social, área de interesse ambiental, área exclusivamente industrial, áreas de preservação permanente e áreas verdes.

Há situações em que o objetivo do planejamento não poderia ser "remover favelas", e sim corrigir os problemas ambientais e urbanos, sem que a população seja removida, pois desfazer uma favela em alguns casos pode ser muito mais danoso do que mantê-las. Para isso o Poder Público deveria fornecer meios para tornar a vida da população mais segura, digna e saudável, dentro do que for viável para cada situação.

No entanto, quando as favelas estão localizadas em áreas de risco (áreas sujeitas a desmoronamentos, inundações ou contaminada) ou quando estiverem situadas em áreas de proteção ambiental, o Poder Público necessariamente precisa remover sua população (MARQUES, 2006).

Juridicamente, considera-se que o Estatuto da Cidade (Lei no.10.257/2001) se posiciona em relação às favelas por meio do usucapião especial de imóvel urbano, quando a ocupação não é de área pública, em seu artigo 10ㅇ.:

As áreas urbanas com mais de duzentos e cinquenta metros quadrados, ocupadas por população de baixa renda para sua moradia, por cinco anos, ininterruptamente e sem oposição, onde não for possível identificar os terrenos ocupados por cada possuidor, são susceptíveis de serem usucapidas coletivamente, desde que os possuidores não sejam proprietários de outro imóvel urbano ou rural.

Nessa situação, existem dois direitos: o dos moradores da favela ao usucapião, e o da sociedade ao planejamento urbano e regional, que visam a propiciar sadia qualidade de vida. Quando impraticável a retirada, é fundamental equipar a área de equipamentos e serviços públicos (MARQUES, 2006). Ao contrário, os programas de regularização fundiária das áreas 
ocupadas devem ter por objetivo principal a integração socioespacial dos assentamentos informais e não somente o reconhecimento da posse para os moradores (ROLNIK et al., 2007).

E, em relação à favela de Pirapozinho, verifica-se possível a permanência de parte da população e remoção da outra parcela. Ou seja, é possível a permanência da da população residente das unidades que estão com as fachadas voltadas para as ruas Francisco Vantini e Profa . Dirce Dias Jorge (Figura 3) e que estiverem em boas condições construtivas, com retirada das demais.

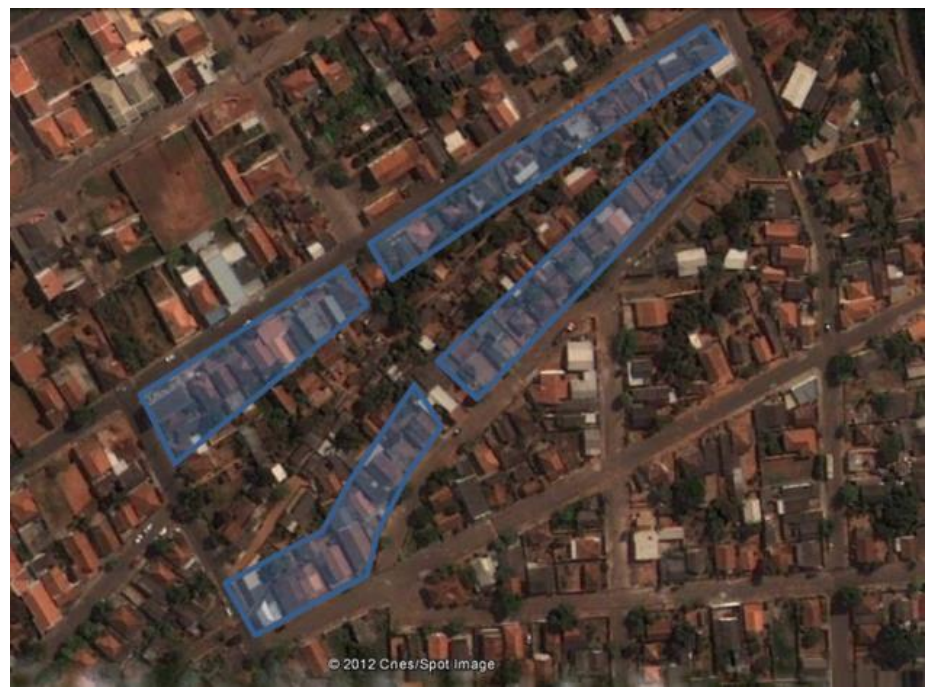

Figura 3. Detalhe das moradas que deveriam permanecer no local

Org: autores, 2012.

Os moradores das unidades residenciais estão voltadas para o interior da quadra, devido à situação precária, deveriam ser removidos para um local adequado, com infraestrutura. A melhor solução seria realocar 24 famílias para o conjunto habitacional em construção no bairro Santa Rosa, vizinho à favela, e o restante para habitações que deveriam ser construídas nos bairros São Francisco e Residencial Rústika, em lotes desocupados.

A intenção seria utilizar os vazios urbanos do município e aproveitar a infraestrutura já existente para integrar os assentados socialmente e espacialmente. Nesse processo, o espaço urbano da cidade seria valorizado, com ocupação adequada dos vazios urbanos, qualificação dos espaços degradados, e uso social da cidade e da propriedade urbana, apoiados pela Constituição Federal de 1988 (artigo 182). 


\section{CONSIDERAÇÕES FINAIS}

Com o estudo realizado no município de Pirapozinho, observou-se que município tem sofrido pela com a postura da Prefeitura Municipal, omissa quanto ao controle e ao planejamento socioespacial urbanos.

E, por meio de análises da cidade, é possível identificar propostas plausíveis de planejamento urbano local, conforme foi apresentado, para a regularização da situação de ocupação residencial dos moradores da favela existente.

Com todas as características verificadas, fica claro que, apesar das favelas fazerem parte da realidade urbana do país, a omissão do Poder Público é marcante, ou por desconsiderá-las ou por não prestar assistência adequada. Omissão e descaso reforçados em uma cidade de pequeno porte como Pirapozinho.

\section{REFERÊNCIAS}

DEÁK, C. Verbetes de economia política e urbanismo. 2011. Disponível em http://www.usp.br/fau/docentes/depprojeto/c_deak/CD/4verb/planejamento-urb/index.html. Acesso em 31 de outubro de 2012.

GOMES, M.T.S. Pirapozinho: uma contribuição ao estudo da expansão da malha urbana. Presidente Prudente: FCT/ Unesp. 1997. (Relatório de Atividades desenvolvidas durante a vigência de Bolsa PAE - Programa de Apoio ao Estudante).

IBGE Cidades. Pirapozinho. 2010. Disponível em http://www.ibge.gov.br/ cidadesat/painel/painel.php?codmun=353920\#. Acesso em 25 de outubro de 2012.

JACOBS, J. Morte e vida de grandes cidades. 3ạ Edição. São Paulo: WMF Martins Fontes, 2011.

MARICATO, E. Brasil, cidades: alternativas para a crise urbana. Petrópolis: Editora Vozes, 2001.

MARQUES, J.R. Desfavelamento - atuação institucional. In: $10^{\circ}$ Congresso de Meio Ambiente e $4^{\circ}$ Congresso de Habitação e Urbanismo do Ministério Público do Estado de São Paulo. 2006. Disponível em http://www.mp.sp.gov.br/portal/page/portal/ cao_urbanismo_e_meio_ambiente/biblioteca_virtual/bv_teses_congressos/Dr.\%20Jos\%C3\%A9\%2 ORoberto\%20Marques.htm. Acesso em 22 de outubro de 2012.

PREFEITURA MUNICIPAL DE PIRAPOZINHO. Lei Ordinária no 3361/2007 - Plano Diretor Urbanístico. Disponível em http://www.leismunicipais.com.br/legislacao-depirapozinho/689924/lei-3361-2007-pirapozinho-sp.html. Acesso em 13 de novembro de 2012.

PRETECEILLE, E.; VALLADARES, L. A desigualdade entre os pobres - favela, favelas. In: HENRIQUES, R.; BARROS, A.R. Desigualdade e pobreza no Brasil. Rio de Janeiro: IPEA, 2000. 
ROLNIK, R. et al. Regularização fundiária sustentável - conceitos e diretrizes. Brasília: Ministério das Cidades, 2007. Disponível em http://www.ebah.com.br/content/ ABAAAAnnIAH/regularizacao-fundiaria-plena. Acesso em 15 de novembro de 2012.

SARAIVA, C.; MARQUES, E. A dinâmica social das favelas da região metropolitana de São Paulo. In: MARQUES, E.; TORRES, H. (org). São Paulo: segregação, pobreza e desigualdades sociais. São Paulo: SENAC, 2005.

VALLADARES. L. A Gênese da Favela Carioca - a produção anterior às ciências sociais. In: Revista Brasileira de Ciências Sociais. Vol.15, n.44, out/2000. pp.5-34.

VILAÇA, F. Espaço intra-urbano no Brasil. 2ạ Edição. São Paulo: Studio Nobel, 2012.

XAVIER, M.C. A ocupação no leito da ferrovia no espaço urbano de Pirapozinho. Presidente Prudente: FCT/UNESP. 2001. (Monografia de Graduação). 